\title{
أثر استخدام الوسائل التعليمية في تعليم اللغة العربية \\ في جامعة إندونيسيا التربوية بجزيرة جاوى الغربية
}

\section{Yufi Mohammad Nasrullah}

e-mail: yufimohammad@uniga.ac.id

Universitas Garut

J1,Raya Semarang, Garut Jawa Barat

\begin{abstract}
This study aimis to: Obtain acquaintance with the importance of Teaching Aids (T.A), and its role in teaching process; To get acquaintance with the problems that confront the using of Teaching Aids (T.A), in teaching Arabic language in Indonesia University of Education; Rising the qualification of the teachers, in employing the Teaching Aids (T.A), in teaching Arabic language; To achieve a futuristic view, that can be reflected in the Teaching Aids (T.A) program, of teaching Arabic language in Indonesia University of Education. The most important of these result are: Using the Teaching Aids (T.A), in teaching Arabic language, has a big role to make the teaching useful for non- Arabic language speakers, where as: (1) It makes the teacher to be an investigator and an executor, instead of to be a commentator and a narrator. (2) It assists to present, perform, control and verify the course in the education situation, as it saves time and sacrificed effort. (3) It brings up students motivation, and encourages them to interact and participate in the lesson, as it develops curiosity by the students. The course which includes Teaching Aids (T.A) will be exiting and understood. It is, no doubt, essential to prepare the teacher of Arabic language for non-native speakers, a professional prepare, according to the designing and using of the Teaching Aids, and drills him to use educational instruments, in order to be accompanying with the technology and the modern demands, and helpful to realize the desired aims. The existence of advanced Teaching Aids (T.A), and using it with suitable way in teaching Arabic language, will assist the teacher to arrive at the required goals in teaching Arabic language.
\end{abstract}

Keywords : Teaching aids, and Teaching Arabic language.

حين، وتبين لنا دور الوسائل التعليمية وأهميتها في

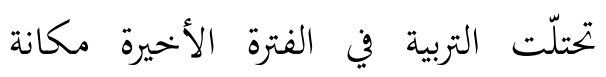

ويتجلى دورها جليًا في التربية والتعليم

الريادة والصدارة بين العلوم، لاسيما في بجال

وهي فن إعداد البشر، ولا شك أن صناعة البشر

البحوث، فالتربية أصبحت علمًا متشعب الفروع

من أنفس الصناعات فالناس هم الذين تقوم على

متنوع الاتجاهات. فلم تعد التربية ذلك الكائن

أكتافهم كل نواحي التنمية فالاهتمام بالأفراد

المتجمد الذي يعتمد على التأديب والتلقين، فما

تربويًا هو اهتمام بجميع مناحي الحياة صناعيًا،

تشرق شمس إلا ونظريات تربوية تصاغ، وبكوث

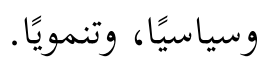

علمية تخرج ومؤلفات متنوعة تطالعنا بين كل 
والحســيث عـن الإطسار النظـــي يقـوم

الكاتب في هذه الدراسة بشرح الإجراءات التي

يتبعها في الجحانب الميداني باعتباره خطوة هامة في

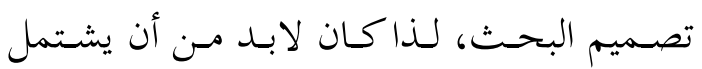

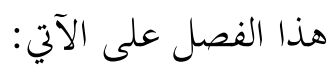

(م-هنهج الدراسة، بجتمع الدراسة، عينة الدراسة،

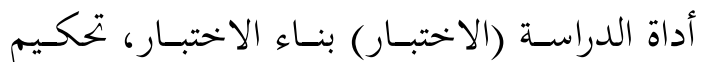
الاختبـار، وصـف الاختبـار بصـورتها النهائيسة، صدق الاختبار، ثبات الاختبار، تطبيق الاختبار، مقيـاس الاختبــار، إعـــاد الاختبـار للتحليـل الإحصــائي، عــرض نتـائج الدراســة الميدانيـة ومناقشتها).

فهـــه الدراســة كـتم بشــرح إجـراءات

الدراسـة الميدانيـة ثم تطبيقهـا في الجحانـب الميـداني

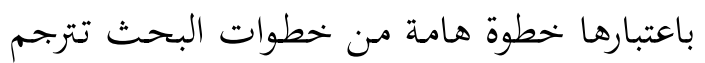

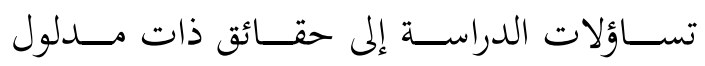
إحصائي محدد.

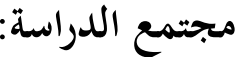

حصرت التجربة في جزيرة جاوي الغربية

في مدينة باندونج بمنطقة سيتيابودي، على طلاب المرجلة الثالثة بحامعة إندزنيسيا التربوية، حيث بلغ بلغ بلغيلغ

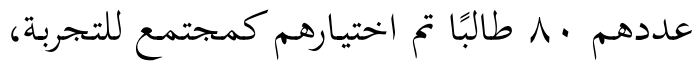
موزعين على بحموعتين تجريبية وضابطة بكل منها
والمراقب لواقع حركة تعليم اللغات في العالم

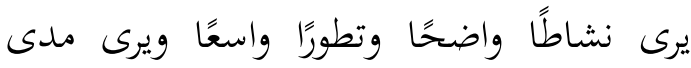
اهتمام الدول والهيئات بقضايا نشر لغاتا فترصد

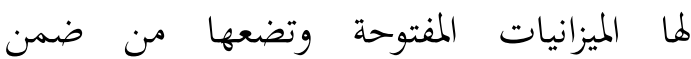
استراتيجياتما السياسية والاقتصادية مستخدمة في ذلك أحدث الوسائل والبحوث. فلا بد من العمل التعاوني بين كل عناصر المنهج (الأهداف والمتوى وطرق التدريس والوسائل التعليمية والنشاط والتقويم) حتى نخرج من مشكلاتنا التعليمية الحالية بحلول ناجعة، حلول تبنى على إطار نظري علمي دقيق يقوم

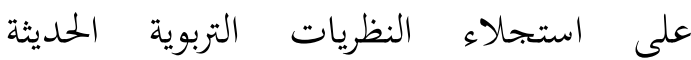
والاستفادة منها في البحالات التعليمية. وبما أن الكاتب قد درّس في إندونيسيا وشاهد الواقع التعليمي فيها ويكفي ما ذكره سابقًا من أن الطالب يتخرج في الجامعة وهو ليس ماهرًا بالمهارات اللغوية الأربع الأساسية فتقابله مشكلات كثيرة أثناء مسيرته التعليمية فيبذل الجهد المضاعف كما يبذل المعلم أيضًا جهلًا كبيرًا ويستغرق وقتًا كثيرًا، وبعد كل هذا الإهدار للزمن والجها لا يسلم الطالب عند ممارسته للغة العربية من الأخطاء الصوتية والتعبيرية. إجراءات الدراسة الميدانية: ع عالبًا. 
ا. ـ الرجوع إلى الدراسات السابقة والبحوث

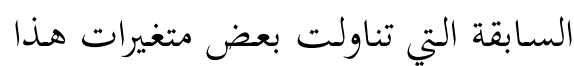

$$
\text { الموضوع. }
$$

r. خبرة الكاتب وممارسته لمهنة التدريس في

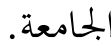

r. سؤال أهل الاختصاص والاستفادة مـن

$$
\text { مقترحاقهم وأرائهم. }
$$

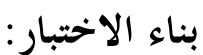

قام الكاتب ببناء الاختبار الذي تكوّن

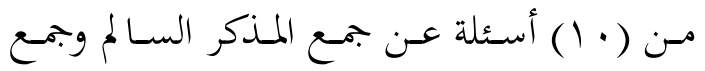

المؤنث السالم.

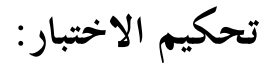

بعد أن قام الكاتب بتصميم الاختبار،

تم عرضه على بحموعة من المحكمين،لمعرفة آرائهم

في مصداقية الاختبارومدى ملاكمته للغرض الذي

صمم من أجله، واتبعنا في ذلك الخطوات التالية:

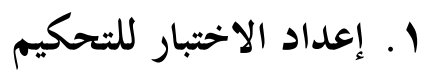

اشتمل الاختبار في صورته الأولية على

مقدمة الاختبار، ذكر فيها الكاتب فكرة

مـوجزة عن موضوع الدراسة، وعنواهـا،

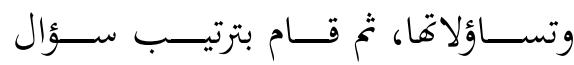

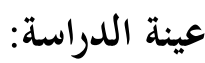

تتكـون مـن الأفراد الممثلـين للمجتمـع

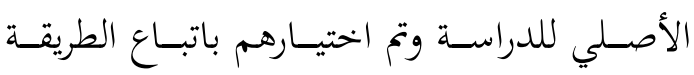

القصـوية في مسـتوى الثالـث بجامعـة إندونيسـيا

التربويـة، تتوزع أفراد العينـة كالتـالي: • م طالبَّا، قسموا إلى بحموعتين هما:

ا ـ البمموعــة التجريبيـة الـتي درســـ باستخدام الوسائل التعليمية.

r. المجموعة الظابطة التي درست بدون استخدام الوسائل التعليمية.

أداة الدراسة (الاختبار)

تعريف الاختبار هو عملية منظمة لقياس

عينة من سلوك الطالب (نتاجات التعلم) وتقييم

هذا السلوك حسب معايير وأعراف معينة.

يحتاج الكاتب لمحاولة الكشف عن صحة

فرضياته، لـذا تم الاستعانة باختبارين تحصيليين،

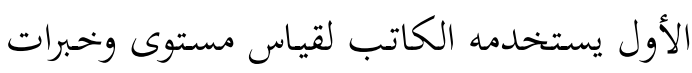

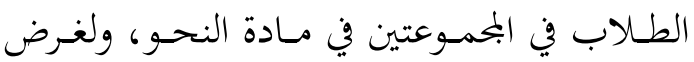

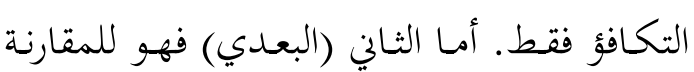

وقياس درجة الكفاءة للأنموذج بعد القيام بأداء

التجربة عملية تطبيق الأنموذج.

قـام الكاتسب بإعـداد وبنـاء الاختبـار بإتبـاع

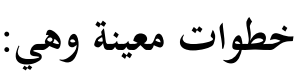




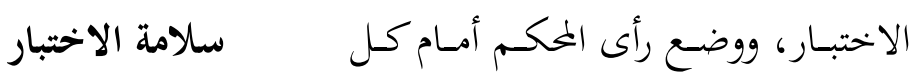

تشير أدبيات التقويم والقياس التي أشرنا

سؤال (مناسبة، غـير مناسبة) ثم أعقـب

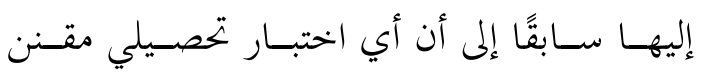

ذلك ما رآه المحكم من إبقاء للسؤال أو مناسهو

شامل ينبغي أن يتم التأكد من سلامته من خحلال

حذف أو تعديل مقترح أو اضافة.

مسألتين أساسيتين، هما:

ץ. توزيع الاختبار على المحكمين

1- معيـار الصـــق، أي أن الاختبـار

بعـــ إعـــاد الاختبــار تم توزيعـه علـى

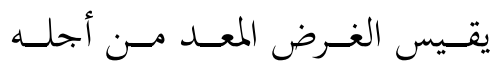

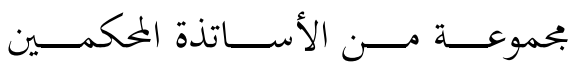

$$
\text { الاختبار أم لا. - الا }
$$

المتخصصين في التربية والمناهج.

r - عامــل الثبــات، اي أن الأســــلة

ب. تصنيف آراء المحكمين

واضـحة ولا تتـأثر بعـاملي الزمـان

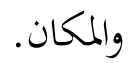

فيمـا يلي وصـف للإجـراءات التي تمـت لضسبط

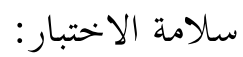

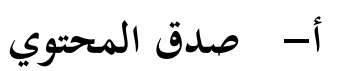

عـرض الاختبـارعلى بحموعـة مسن

المختصـين في اللغـة العربيـة وبعـض

وصف الاختبار في صورته النهائية:

المعلمــين الــذين درســوا النحــــو

قـام الكاتـب بـإجراء التعـديلات المناسبة

لطلاب المرحلة الثالثة، ولهم خلفية

بنـاء على مـا ورد مـن ملاحظات ومقترحات مـن

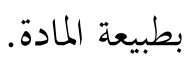

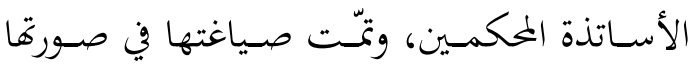

\section{ب- - صدق المحك} النهائية مشتملة على ما يلي:

تم تدقيق الأسئلة تبعًا لمحتوى المادة

ا ـ اشتمل الاختبـارعلى عشرة (• () أسئلة

التعليمية كما جاء في كتاب النحو

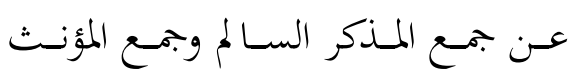


الطـلاب، أمـا المحموعــة التجريبيـة فقـــ تم بنـاء الانموذج وتطبيقه على الطلاب بطريقة متسلسلة ومتوازنة باستخدام الوسائل التعليمية.

\section{المعالجة الإحصائية}

تمـت معالجــة البيانـات إحصـائيا بعـد

استشــارة عــدد مــن المختصــين في البحــوث والإحصــاء، حيــث تم اسـتخدم طريقــة الحــزم الإحصائية (Spss)، وذلك لحساب: التكرارات والنسـب المئويـة والمتوسطات الحسـابية لكل عينـة على حـده، والانحرافات المعيارية، واختبار للدلالة الفروق في الإجابات، وعمل رسوم بيانية للبيانات

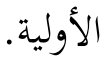

القانون الإحصائي الذي استخدم في البحث: لقـد تعامـل الكاتـب مـع بحموعـة مـن

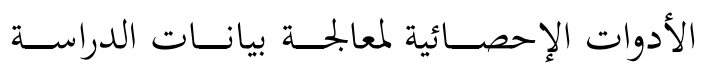
الميدانية. وقد تمثلت في:
للمرحلة الثالثة. تأليف (مامن عبد

$$
\text { الرحمن) طبع سنة ا . . بام. }
$$

تطبيق الاختبار:

لقــــــم تطبيـق الاختبــار علــى عينــة

الدراسة في المرحلة الثالثة، وقد قام الكاتب بتوزيع الاختبـار علـى عينـة الدراسـة بجامعـة أندونيسـيا التربوية في منطقة جاوى الغربية. وكان عدد العينة في هذا الاختبار ثمانين ( • م) طالبًا.

تطبيق التجربة:

بــــأت عمليـــة التطبيــق التجربــــة في المحمـوعتين في آن واحسد وكـان الكاتـب يدرسهما طوال الأسبوع كما عمد الكاتب أن يهيئ نفس الظروف مـن حيـث المـادة وزمسن الحصص بـنمط واحـــ عـدا الاخـتلاف الرئيس في عمليـة تصـميم مادة الدرس وطريقة تدريسها، حيث ظل الكاتب يدرس البمموعة الظابطة بالطريقة التقليدية التي تم وصـفها بطريقـة متسلسـلة ومتوازنـة كمـا اعتـاد الاختبار التائي

$$
r^{b}-1 b
$$

$$
\begin{aligned}
& (1+1)(r \varepsilon r u+1 \varepsilon l u) \\
& \text { نا نَ }
\end{aligned}
$$




$$
r-r \dot{0}+1 \dot{0}
$$

$$
\begin{aligned}
& \text { ק| = متوسط درجات العينة الأولى } \\
& \text { ק = = متوسط درجات العينة الثانية } \\
& \text { عا = الانحراف المعياري للعينة الأولى } \\
& \text { عr = الاخراف المعياري للعينة الثانية } \\
& \text { ن = عدد أفراد العينة الأولى } \\
& \text { نץ = عدد أفراد العينة الثانية }
\end{aligned}
$$$$
\text { حيث }
$$

وقـد أُستخدمت هـذه المعادلة لإيجاد الفروق بـين المجمسوعتين التجريبيـة والضـابطة في اثر استخدام

$$
\begin{aligned}
& \text { الوسائل التعليمية. } \\
& \text { ( O O O }
\end{aligned}
$$

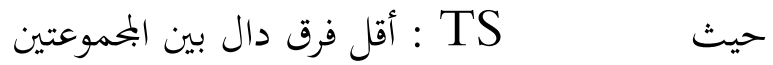

$$
\begin{aligned}
& \mathrm{S} 2=(\alpha-1) \mathrm{f} \alpha-1 . \mathrm{y} \\
& \text { fo-1 . y } \\
& \text { 枉 } \\
& \text { =q,T = }=q \alpha-y \\
& \alpha \\
& \text { = درجات حرية الخطأ y }
\end{aligned}
$$




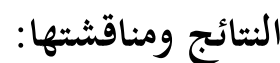

قام الكاتب بتقسيم عينة الدراسة البالغ

عددهم (•) طالبًا إلى بحموعتين إلى كل بحموعة تحتوي على (• ع) طالبًا.

البمموعة الأولى: الضابطة وقد درست

بدون استخدام الوسائل التعليمية بواقع محاضرتين على مدى أسبوعين بواسطة أستاذ مادة النحو

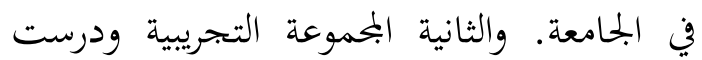

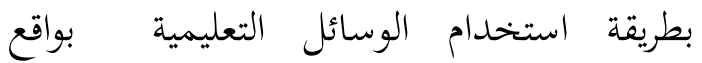
محاضرتين في خلال أسبوعين بواسطة أستاذ المادة

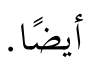

وقد كان الجحانب العلمي من الدراسة عبارة عن تدريب الطلاب على بعض الدروس في اللغة العربية (النحو) وكانت الدروس تخص درس الجمع المذكر السالم وجمع المؤنث السالم. وقد هدف الاختبار إلى قياس تحصيل الطلاب لأساسيات في تحصيل الدروس سابقة

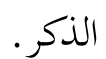

وقد قام الكاتب باستخدام اختبارين :

قبلي وبعدي, اختبار قبلي (أي قبل استخدام الوسائل التعليمية في تدريس الطلاب) لمعرفة مدى بتحانس العينة المختارة ولتحديد المجموعتين (الضابطة والتجريبية).

وكذلك استخدم الاختبار البعدي (أي

بعد استخدام الوسائل التعليمية في تدريس الطلاب) لقياس تدريس الطلاب في درس المذكر السالم والمؤنث السالم بعد تدريسها مباشرة, وتم
إعداد الصف للاختبار بواسطة أستاذ المادة. وقد أخذ في الاعتبار، الإضاءة والتهوية والجلسة الصحيحة والوضع النفسي والجسمي والعقلي.

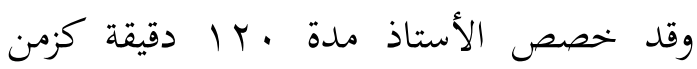
لإجراء الاختبار, منها 10 دقيقة للإرشادات

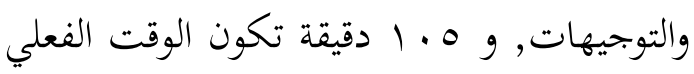
للإجحابة على أسئلة الاختبار.

كما حددت درجة الاختبار بالرقم الدال على عدد الإجابات الصحيحة سجلها

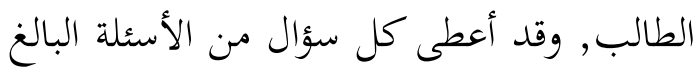
عددها (•r) سؤال الدرجة النهائية للاختبار

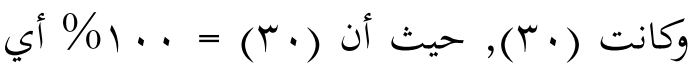
الدرجة الكاملة. كما أهمل الكاتب السؤال الذي أجاب عليه الطالب بأكثر من إجابة واحدة. بعد الانتهاء من تصحيح الاختبارين

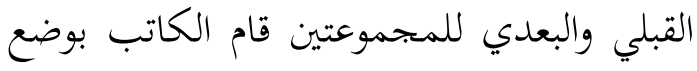
الدرجات الخام في جدول خاص وأجري عليها عملية التباين للاختبار القبلي والبعدي وتحليل

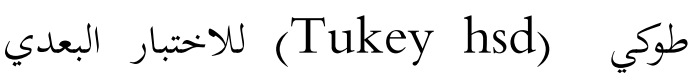

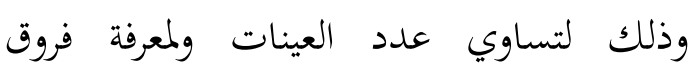
التحصيل بين المجموعتين التجريبية والضابطة.

الاختبار التحصيلي للطلاب:

بعد الانتهاء من تصحيح أوراق إجابات الطلاب للمجموعتين والذين درسوا بطريقتين مختلفتين (باستخدام وسائل وبدون استخدام وسائل). 
وأجريت عملية التحليل الإحصائي

لدرجات الطلاب الخام (انظر الملاحق) بواسطة

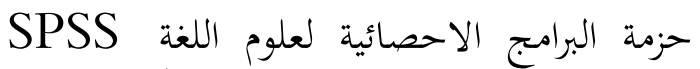

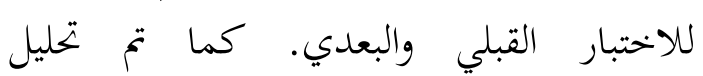

الطوكي (Tukey HSD) للمقارنة المتعددة في الاختبار البعدي لمعرفة فروق التحصيل بين البجموعتين. وفيما يلي عرض لتحليل التباين الأحادي للاختبار القبلي للمجموعتين.

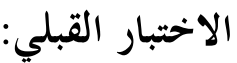

جدول رقم (1) يوضح مزاوجة عينات الإحصاء

\begin{tabular}{|c|c|c|c|c|}
\hline الوسط الحسابي & الانخراف المعياري & العدد & قيمة احتمالية & \\
\hline $1 . \cdot r \cdot q$. & 7.01999 & $\varepsilon$. & $1 \leq .00 \ldots$ & التجريبية \\
\hline $1.10 . \leqslant V$ & $V . Y V T 19$ & $\varepsilon$. & 10. Vo. & الضابطة \\
\hline
\end{tabular}

جدول رقم (r) يوضح مزاوجة عينات الربط

\begin{tabular}{|c|c|c|c|}
\hline Sig & الربط & العدد & \\
\hline$\cdots$ & . $94 \pi$ & $\varepsilon$. & والضابطة منفرد التجريبية \\
\hline
\end{tabular}

جدول رقم (r) يوضح اختبار العينة المزدوجة

\begin{tabular}{|c|c|c|c|c|c|c|}
\hline \multirow{3}{*}{ ت } & \multicolumn{5}{|c|}{ الفروق } & \\
\hline & \multicolumn{2}{|c|}{ \% \% ثقة فاصلالفروق } & \multirow{2}{*}{ الالمعراف } & \multirow{2}{*}{ الوسط } & \multirow{2}{*}{ قاحتمالية } & \\
\hline & أعلى & أدنى & & & & \\
\hline$-1.1 \mathrm{NT}$ & rVTYY & -1.ETTVT & . & r.1.1.1 & $-.040 \%$ & زالضابطة منفرد التجريبية - \\
\hline
\end{tabular}

جدول رقم (ع) يوضح اختبار العينة المزدوجة 


\begin{tabular}{|c|c|c|}
\hline Sig. (2-tailed) & Df & \\
\hline$. T \leqslant 0$ & rq & زوج منفرد التجريبية - الضابطة \\
\hline
\end{tabular}

يتضح من خلال الجلداول وجود بتحانس بين البمموعة الضابطة التي درست بدون استخدام الوسائل التعليمية والمحموعة التجريبية التي درست باستخدام الوسائل التعليمية في الدرجة الكلية للاختبار القبلي

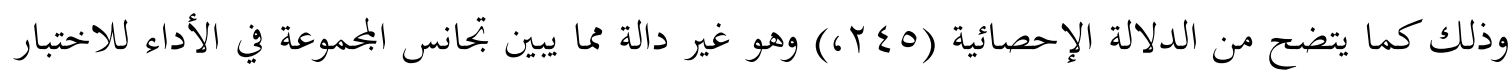
وذلك يتحقق الفرض الأول للاختبار.

توجد فروق ذات دلالة إحصائية بين تدريس اللغة العربية (النحو) باستخدام الوسائل التعليمية وتدريسها بدون استخدام الوسائل التعليمية في جامعة إندونيسيا التربوية في التحصيل البعدى في المتوسط.

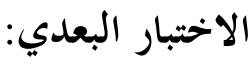
جدول رقم (0) يوضح مزاوجة عينات الإحصاء

\begin{tabular}{|c|c|c|c|c|c|}
\hline الوسط الحسابي & الاخراف المعياري & العدد & قيمة احتمالية & & \\
\hline I.人r人Tr & $11.7477 \varepsilon$ & $\varepsilon$. & $11.0 Y 0$. & التجريبية & زوج منفرد \\
\hline $1 . T 17 . V$ & N.TYTOO & $\varepsilon$. & 7r.oro. & الضابطة & \\
\hline
\end{tabular}

$$
\text { جدول رقم (†) يوضح مزاوجة عينات الربط }
$$

\begin{tabular}{|c|c|c|c|}
\hline Sig & الربط & العدد & \\
\hline.$V T \varepsilon$ &.- .00 & $\varepsilon$. & والضابطة منفرد التجريبية \\
\hline
\end{tabular}


جدول رقم (V) يوضح اختبار العينة المزدوجة

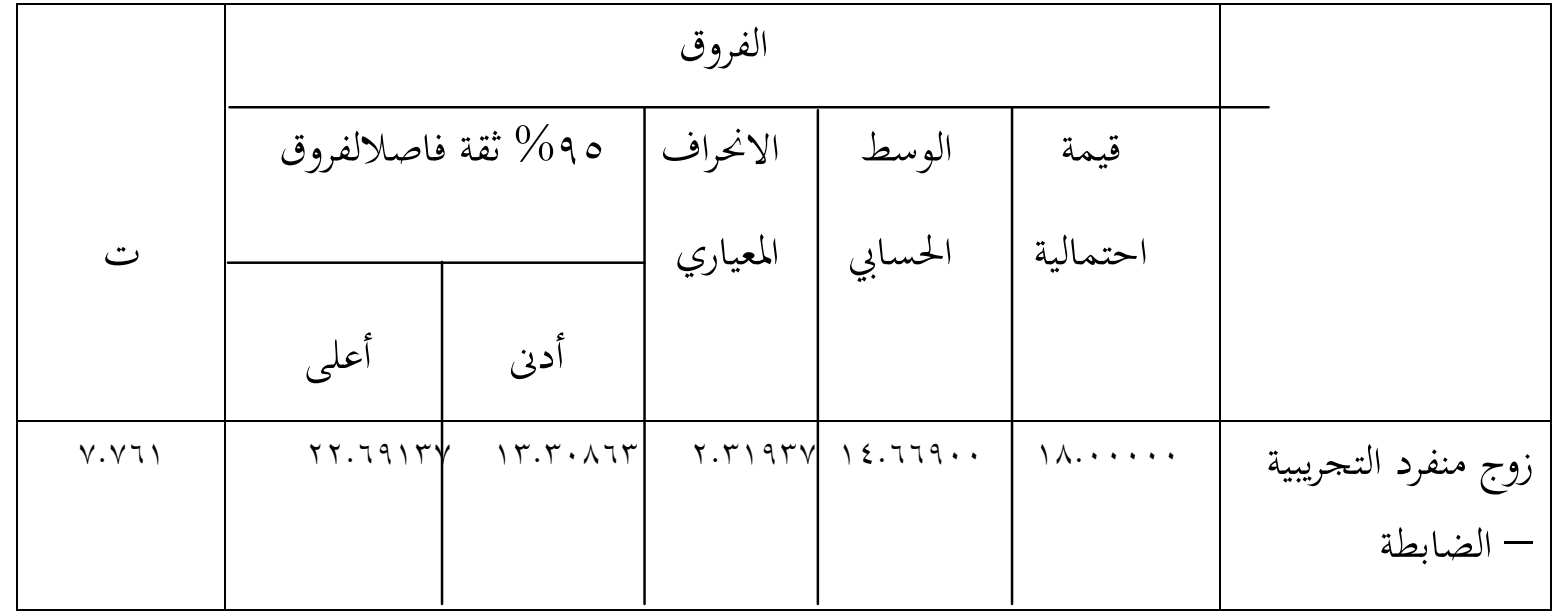

جدول رقم (^) يوضح اختبار العينة المزدوجة

\begin{tabular}{|c|c|c|}
\hline Sig. (2-tailed) & Df & \\
\hline$\ldots$ & $\mu q$ & زوج منفرد التجريبية - الضابطة \\
\hline
\end{tabular}


يتضح من خلال الجداول الموضحة

أعلاه بما أن الدلالة (...6) أصغر من (1.، ·.)

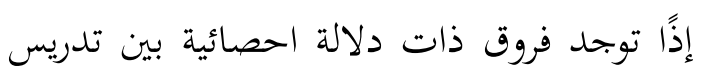

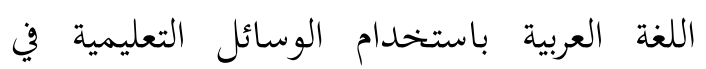

التحصيل البعدى في المتوسط عند المستوى دلالة

(1 ، ، ) وبذلك يتحقق الفرض للاختبار.

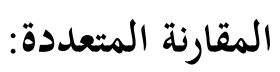

نظرًا لتساوى حجم العينة في المجموعتين

ولمعرفة الفروق الاحصائية بين البحموعتين ولمعرفة لفينة

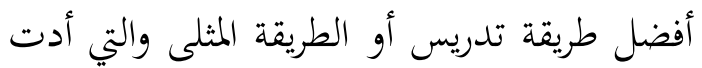
إلى تحصيل دراسي جيد في تحليل الدرجات الخام للطلاب باستخدام معادلة طوكى. الفرض تحت الاختبار: توجد فروق ذات

دلالة احصائية بين استخدام الوسائل التعليمية في تدريس اللغة العربية بيامعة إندونيسيا التربوية وتدريس اللغة العربية بدون استخدام الوسائل

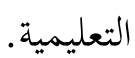

يتضح من خلال التحليل أنه توجد

فروق ذات دلالة إحصائيية بين تدريس اللغة العربية باستخدام الوسائل التعليمية وتدريس اللغة العربية بدون استخدامها في جامعة إندونيسيا التربوية ترجع لصالح استخدام الوسائل التعليمية في تدريس اللغة العربية عند مستوى دلالة (0 •، •) وبذلك يهقق الفرض للاختبار.
لإجراء المقارنة في الاختبار القبلي وفقًا

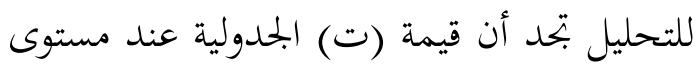

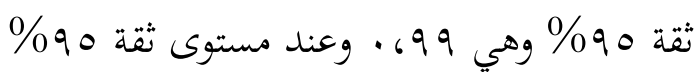
وهي أدنى

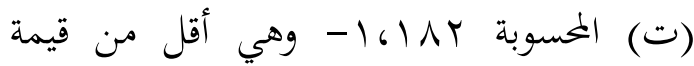
(ت) الجدولية وهذا يدل على عدم وجود فروق ذات دلالة إحصائية بين المجموعتين وعليه يمكن اعتبار المحموعتين متماثلتين ومتجانسين.

تمثل الأولى منها البمموعة الضابطة والأخرى المجموعة التجريبية ومن خلال مقارنة

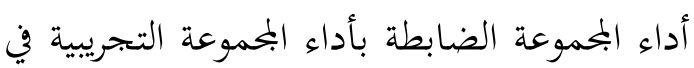
الاختبار البعدي يمكن إيجاد الوسط الحسابي

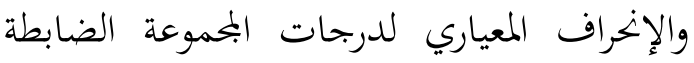
والتجريبية في الاختبار البعدي وإيجاد قيمة (ت)

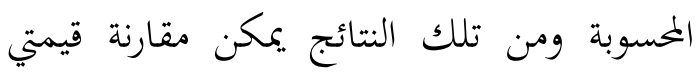
الوسط الحسابي والإخراف المعياري لدرجات المحموعة الضابطة والتجريبية في الاختبار البعدي الخحراف البعاري ويمكن إجراء المقارنة حيث بند قيمة (ت) الجدولية عند مستوى ثقة 09\% مستوى أدنى

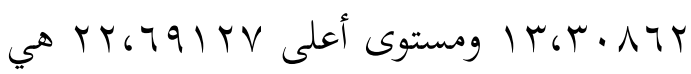
لفإن هذا يدل على وجود فروق ذات V.VTI دلالة احصائية بين افراد البمموعتين الضابطة والتجريبية في الاختبار البعدي ترجع لصاحلح البمموعة التجريبية والتي درست باستخدام الوسائل التعليمية. 


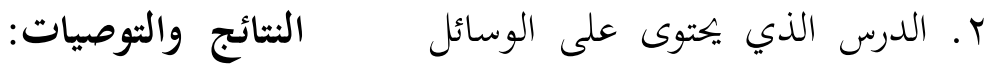

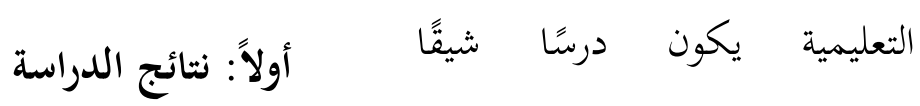

توصلت الدراسة لبعض النتائج التي يأمل

ومفهومًا.

الكاتب أن تسهم في معالجة مشكلات استخدام

r. إعداد معلم اللغة العربية لغير

الوسائل التعليمية في تدريس اللغة العربية في

الناطقين بها إعدادًا مهنيًا في إطار

$$
\text { جامعة إندونسيا التربوية وهي: }
$$

إعداد وتصميمها

واستخدامها وتدريبه على استعمال

1. استخدام الوسائل التعليمية في تعليم

اللغة العربية لها دور في بناح عملية

الأجهزة التعليمية حتي يصبح مواكباً

لمتطلبات العصر والتكنولوجيا أمًا

التعليم للناطقين بلغات أخرى

$$
\text { حيث اها تسهم في لمئم }
$$

أ. تجعـل المعلـم محققــاً ومنفـذاً

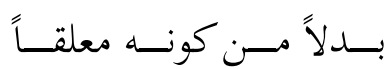

وناقلاً.

ضروريًا دون شك ويساعد في تحقيق

$$
\text { الأهداف المطلوبة. - إن }
$$

ع. وجود الوسائل التعليمية المتطورة

واستخدامها بطريقة مناسبة في

تعليم اللغة العربية يساعد المعلم

ب. تسـاعد على عـرض المـادة

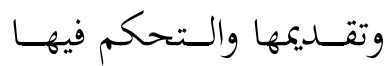

للوصول إلى الأهداف المطلوبة في

$$
\text { تعليم اللغة العربية. }
$$

وإدارة الموقـــف التعليمــي

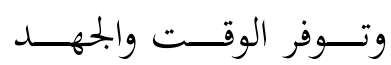

$$
\text { ثانيًا : التوصيات }
$$

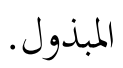

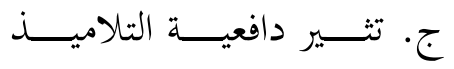

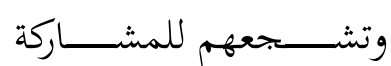

والتفاعل مع الدرس وتنمي

بنـاء علـى النتـائج الـتي توصـل إليهـا

الكاتب في هذه الدراسة، يوصي بالأمورالآتية:

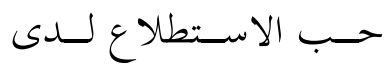

1. السعي لتوفير الوسائل التعليمية والأجهزة

في تعليم اللغـة العربيـة لجامعـة إندونيسيا

التربوية.

التلاميذ. 
r. تدريب وتأهيل المعلمين لاستخدام الوسائل التعليمية في عملية التدريس.

r. تشجيع معلمي اللغـة العربية في جامعـة

إندونيسيا التربوية على استخدام الوسائل التعليمية في عملية التدريس.

ـ. ضـرورة تـدريس المبتدئين في تعليم اللغـة

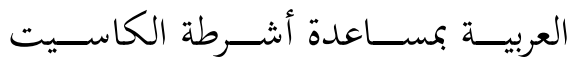

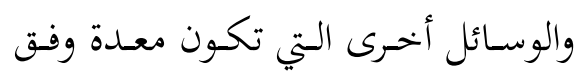

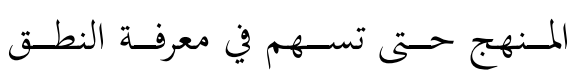

الصـحيح للكلمـات وتعزز مـن عمليـة

$$
\text { التعليم الذاتي للمتعلم. }
$$

ه. (مقد المؤتمرات والندوات لمناقشة البحوث

والدراسات التي قدمت في بحال الوسائل

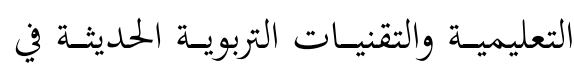

$$
\text { تعليم اللغة العربية. }
$$

ج. التوسع في استخحدام الوسـائل التعليميـة

الحديثة التي تؤدي إلى رفع كفاءة العملية

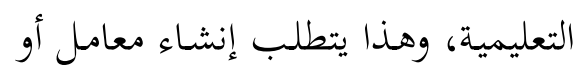

مراكـز للوسـائل التعليميـة تخـدم عـددًا معينًا من المدارس.

V. إعـــاد وبتهيـز جميـع الوسـائل والمــواد

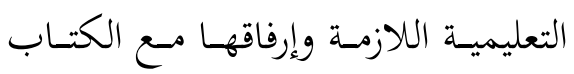

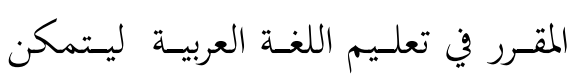

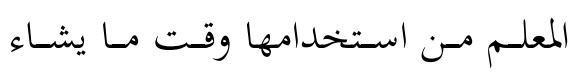

ودون أن يواجه أدني صعوبة في تجهيزها.

ᄉ. على جامعـة إندونيسيا التربوية أن تقوم

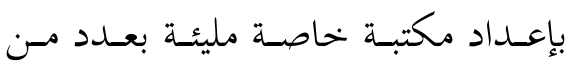

الوسائل التعليميـة المستخحدمة في تعليم

اللغـة العربيـة مثـل: الصـور والرسـومات التحات

والآلات التوضيحات وغيرها حتى يلجأ

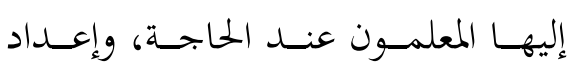

$$
\text { المنهج الالكتروني. }
$$

9. استمرارية تدريب المعلمين بصورة متنوعة

ومحددة حسب خبراقم وأن يتطور هـا

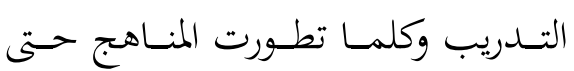

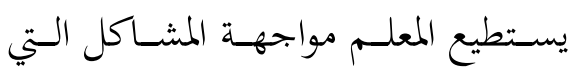

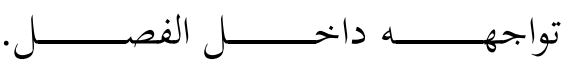




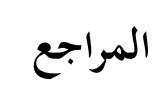

Abdul Hafidz Salamah (2000), Al Wasail At Ta'limiyyah wa Al Manhaj, Dar Al Fikr, Omman.

Abdul Hamid Abdullah wa Nashir Abdullah Al Ghali, (2000), Asas I'dad Al Khuthat li Ghairi An Nathiqina bi Al 'Arabiyah, Dar Al Ghali, Riyadh.

Abdul Majid Sayyid Ahmad Mansur (1981), Sikologiyah Al Wasail At Ta'limiyyah wa Wasail Tadris Al Lughah Al Arabiyyah, Dar Al Ma'arif, Cairo.

Abdul Rahman Kaduk (2000), Teknologiya Ta'lim, Dar Al Ghali, Riyadh.

Ahmad Khairi Kadhim (19820, Al Wasail At Ta'limiyyah wal Manhaj, Dar An Nahdhah Al 'Arabiyyah, Cairo.

Ahmad Salibi (1979), Mausu'ah at tarikh Al Islami Wal Hadharah Al Islamiyyah, Maktabah An Nahdhah Al Misriyyah, Cairo.

Ali Sya'ban (1995), Qira'at fi Ilmi Al Lughah At Tathbiqi-Ta'rif wa Tahrir, Beirut, Libanon.

Basyir Abdul Rahman Al Kalubi (1977), Al Wasail At Ta'limiyyah I'daduha wa Thuruku Isti'maliha, Dar Al Kolam Lil Malayin, Beirut.
Basyir Abdul Rahman Al Kalubi (1999), At Teknologiyya fi 'Amaliyyah At Ta'allum wa At Ta'lim, Dar As Syuruk Lin Nasyri wa At Tauzi', Oman.

Husain HamadiAt Thabiji (1984), Wasail Al Ittishal wa At Teknologiya fi At Ta'lim, Dar Al Kolam, Kuwait.

Ibrahim Muthawi' (1979), Al Wasail At Ta'limiyah, Maktabah AnNahdhah Al Mishriyyah, Cairo.

Panikar (1964), Asia wa As Saitharah Al 'Arabiyyah, Tarjamah

'Arabiyyah Al Haiah Al 'Amah Lil Kitab, Cairo.

Shalah Abdul Majid 'Arabi (1981), Ta'allum Al Lughat Al Hayyah wa Ta'limuha baina An Nadhariyat wa At Tathbiq, Maktabah Lubnan, Libanon.

Syadi Ahmad Thabi'I (1989), Mafhum Al Manhaj wa 'AnashirihiTa'lim Al 'Arabiyyah li Ghairi An Nathiqina biha-Manahijuhu wa Asalibuhu, Al Munadhomah Al Islamiyyahli At Tarbiyah As Tsaqofah wa Al Ulum, Riyadh.

Umar As Siddiq Abdullah (1977), Al Wasail At ta'limiyah, Beirut, Libanon. 